\title{
Influence of microclimatic conditions under high tunnels on the physiological and productive responses in blueberry ' $O$ 'Neal'
}

\author{
Jorge Retamal-Salgado ${ }^{1}$, Richard M. Bastías $^{1^{*}}$, Rosemarie Wilckens ${ }^{1}$, and Leandro Paulino ${ }^{1}$
}

\begin{abstract}
Blueberry (Vaccinium corymbosum L.) production under tunnels has spread in recent years. However, there is little information on the productive and physiological responses of blueberry grown under high tunnels. The objective of this research was to evaluate the effect of high tunnel microclimate on the physiological and productive responses of blueberries. A total of 1296 plants of highbush blueberry 'O'Neal' were grown in high tunnels, leaving the same amount of plants under open fields (control). Environmental temperature $\left(\mathrm{T},{ }^{\circ} \mathrm{C}\right)$ and relative humidity $(\mathrm{RH}, \%)$, diffuse and total photosynthetically active radiation $\left(\mathrm{PAR}_{\text {diffuse }}\right.$ and $\left.\mathrm{PAR}_{\text {total }}, \mu \mathrm{mol} \mathrm{m} \mathrm{m} \mathrm{s}^{-1}\right)$, stomatal conductance $\left(g_{s}, \mathrm{mmol} \mathrm{m}^{-2} \mathrm{~s}^{-1}\right)$ and maximum photochemical efficiency of photosystem II $\left(F_{v} / F_{m}\right)$ of the leaf were measured. Fruit yield, date of harvest initiation and fruit growth rate were also determined. The maximum $\mathrm{T}$ was on average $10-12{ }^{\circ} \mathrm{C}$ higher inside the high tunnel than the control, whereas the minimum $\mathrm{T}$ averaged only $2-5^{\circ} \mathrm{C}$ higher. PAR total decreased an average of $25 \%$ under tunnel, while levels of PAR diffuse increased more than $150 \%$. The $g_{s}$ ranged between $42 \%$ and $99 \%$ higher in the high tunnel compared to the control, and was positive and statistically related $\left(\mathrm{r}^{2}=0.69 * *\right)$ to $\mathrm{PAR}_{\text {diffuse }}$ variations. Blueberries under high tunnel recorded an accumulated yield $44 \%$ higher, while harvest started $14 \mathrm{~d}$ earlier compared to control. The results suggest that high tunnels in blueberries increases fruit yield and improves precocity due to higher temperatures during the flowering stage and fruit set. Particular light conditions under tunnels would favor higher leaf stomatal conductance in this crop.
\end{abstract}

Key words: Light conditions, productivity, protected crops, temperature, Vaccinium corymbosum.

\section{INTRODUCTION}

Blueberry production in protected greenhouses or plastic tunnels has spread in recent years because it prevents spring frost damage during flowering and fruiting stages, as well as rain damage at harvest. In fact, this technique could be increasingly necessary to mitigate adverse effects of climate change on fruit growing (Carlen and Krüger, 2009). Production under high tunnels can improve fruit precocity, allowing growers to get the premium prices usually occurring early in the harvest season (Demchak, 2009). Protecting crops under plastic (polyethylene), either with high tunnels or greenhouses, generates changes in the environmental conditions of light, temperature and relative humidity that may have effects on the productive and physiological responses of the plant (Li et al., 2012). Effects on non-woody species, such as ornamental and vegetables (Zhao et al., 2014.) have already been described. However, little information exists on the physiological and productive changes in woody plants, such as blueberries (Demchak, 2009). Studies have shown that air temperature inside the tunnel is 3 to $20{ }^{\circ} \mathrm{C}$ higher and that soil temperature is $2-5^{\circ} \mathrm{C}$

${ }^{1}$ Universidad de Concepción, Facultad de Agronomía, Av. Vicente Méndez 595, Chillán, Chile.

*Corresponding author (ribastias@udec.cl).

Received: 15 October 2014.

Accepted: 8 April 2015.

doi:10.4067/S0718-58392015000400004 higher than soil temperatures recorded in open fields (Ogden and van Iersel, 2009; Zhao et al., 2014). Studies conducted in tomatoes and strawberries indicate that the increase in temperature in high tunnels directly influences fruit precocity, with a harvest starting between 7 and 21 $\mathrm{d}$ earlier than in the open field (Wien, 2009; Singh et al., 2012; Cowan et al., 2014; Zhao et al., 2014). An increase in temperature of $2-3{ }^{\circ} \mathrm{C}$ and in relative humidity of $2-6 \%$ has been reported in strawberries grown under tunnels (Singh et al., 2012). Temperature and relative humidity play an important role in leaf stomatal conductance $\left(g_{s}\right)$, and therefore in the transpiration rate and photosynthesis of the plant (Righi et al., 2012).

Polyethylene films that are commonly used to cover greenhouses or tunnels can reduce transmission of photosynthetically active radiation (PAR) between $20 \%$ and $30 \%$ compared to radiation under unprotected conditions (Cowan et al., 2014). It has been found that a decrease in PAR availability may have negative effects on crop production under plastic because it decreases photosynthesis rate, which in turn affects yield and quality (Sandri et al., 2003). However, it has also been reported that a 40\% decrease in PAR has no effects on the photosynthetic efficiency of blueberries (Lobos et al., 2012).

Studies in other fruit species have suggested that a reduction in radiation levels positively affects the net photosynthesis of the plant by increasing $g_{s}$ and intercellular $\mathrm{CO}_{2}$ concentration (Corelli-Grappadelli and Lakso, 2007). It has been demonstrated that the photosynthetic capacity 
on citrus trees can improve when PAR decreases, reducing photoinhibition by excess light, which consequently improves the photochemical efficiency of photosystem II (Medina et al., 2002). A decrease in PAR availability can also induce photo-morphogenetic responses associated with the phenomenon known as 'shade avoidance' whose response is regulated by phytochrome activity altering shoot elongation and leaf area with ensuing effects on photo-assimilate partitioning and fruit growth (Bastías et al., 2012).

The objective of this research was to evaluate the effect of the microclimate conditions existing in high tunnels on productive and physiological responses in blueberries.

\section{MATERIALS AND METHODS}

\section{Experimental design and orchard management}

The study was conducted during the 2011-2012 blueberry growing season, in an area $\left(37^{\circ} 6{ }^{\prime} 31^{\prime \prime} \mathrm{S}, 7^{\circ} 25^{\prime} 57^{\prime \prime}\right.$ W) located in the Biobío Region, Chile. The trial was conducted in a commercial orchard of highbush blueberry (Vaccinium corymbosum L.) 'O'Neal' planted in 2010 on a sandy loam soil. Water was supplied by drip irrigation system with drip emitters of $2 \mathrm{~L} \mathrm{~h}^{-1}$ and spacing at $30 \mathrm{~cm}$. Orchard management of fertilization, pruning, and pest control was realized according standard procedures for this crop in Chile (Sudzuki, 2002).

A treatment was set up on a high tunnel structure of $5.5 \mathrm{~m}$ wide, $51 \mathrm{~m}$ long, and $3.5 \mathrm{~m}$ tall, with metal frames. Four tunnels covered with a polyethylene film (Alcudia LDPE 2303FL, Repsol S.A., Madrid, Spain) of $200 \mu$ thick, with $85 \%$ PAR transmission capacity, $13 \%$ infrared radiation (IR) and 60\% visible light dispersion were used, covering a total of 1296 plants. The polyethylene film was placed over the orchard $35 \mathrm{~d}$ before full bloom and was completely opened at $60 \mathrm{~d}$ after full bloom (DAFB). The tunnels were designed with lateral sliding windows to facilitate removal of heat and ventilation. These windows were manually opened when internal temperature reached $21{ }^{\circ} \mathrm{C}$ and closed in the afternoons when temperature decreased below $10{ }^{\circ} \mathrm{C}$. Side walls of the high tunnels were kept open from November 15.

For each treatment, plants were planted on four raised beds of three rows, with a plant spacing of $0.45 \mathrm{~m} \times 0.45$ $\mathrm{m}$ (11 000 plants ha-1). The control treatment included the same number of raised beds, rows and plants, but these were grown in open fields. The experiment was conducted in a completely randomized design and included six plants in the central row of each raised bed per treatment, with a total of 24 plants per treatment (replicates). Both treatments were managed similarly in terms of plant sanitary control, fertilization and irrigation. To improve the effectiveness of pollination, four bumblebee hives were introduced (Natupol, hive class C, Koppert Biological Systems, Berkel en Rodenrijs, the Netherlands) under tunnels and in the open field conditions.

\section{Characterization of the environmental conditions}

Air temperature $\left({ }^{\circ} \mathrm{C}\right)$ and relative humidity (RH, \%) were measured both outside and inside the tunnels at 15 min intervals by using automatic sensors, model KeyTag (KeyLog Recorders, USA). The sensors were placed in the center of the orchard and at $1.2 \mathrm{~m}$ above the ground. Variations in light conditions were quantified in terms of the total photosynthetically active radiation $\left(\mathrm{PAR}_{\text {total }}\right)$ and diffuse photosynthetically active radiation $\left(\mathrm{PAR}_{\text {diffuse }}\right) \mathrm{using}$ a quantum sensor, model Delta T (Delta-T Devices Ltd., Cambridge, UK). The photosynthetic photon flux density (PPFD, $\mu \mathrm{mol} \mathrm{m} \mathrm{m}^{-2} \mathrm{~s}^{-1}$ ) was measured at 09:00, 12:00, and 15:00 h on completely sunny and partly cloudy days. The PAR $_{\text {diffuse }}$ was estimated according to the method adapted and proposed by Al-Helal and Abdel-Ghany (2010), placing an opaque disk at a distance of $50 \mathrm{~cm}$ from the PAR sensor and covering it with the shade of the disk in a $100 \%$.

\section{Chlorophyll fluorescence and stomatal conductance}

Maximum $\left(F_{m}\right)$ and minimum chlorophyll fluorescence $\left(F_{o}\right)$ were measured in two moments ( $1 \mathrm{wk}$ before of polyethylene film was opened) under a partly cloudy day condition and under a sunny day condition, using a portable fluorometer (model OS-30p, Opti-Sciences, Hudson, New Hampshire, USA), while variable fluorescence $\left(F_{v}=F_{m}-F_{o}\right)$ was determined according van Kooten and Snel (1990). Measurements were made at three different times of the day (09:00, 12:00, and 15:00 h) in the $5^{\text {th }}$ well-lit leaf from annual shoots. Both $F_{o}$ as $F_{m}$ were determined after leaves were dark-adapted for 30 min (Reyes-Diaz et al., 2009), using leaf clips with sliding shutters. Based on these parameters, the photochemical efficiency of photosystem II $\left(\mathrm{F}_{\mathrm{v}} / \mathrm{F}_{\mathrm{m}}\right)$ was determined using the relationship given by van Kooten and Snel (1990) $F_{v} / F_{m}=\left(F_{m}-F_{o}\right) / F_{m}$. The photoinhibition degree was determined by the fluorescence parameter $F_{v} / F_{m}$ at different times of the day with respect to the value recorded in the morning. Stomatal conductance $\left(g_{s}\right.$, mmol $\left.\mathrm{m}^{-2} \mathrm{~s}^{-1}\right)$ was measured using a portable porometer, model AE4 (Delta-T Devices Ltd.) Both stomatal and chlorophyll fluorescence measurements were performed simultaneously, using well-lit leaves from the same plants and shoots for all of them.

\section{Fruit growth rate, yield, and precocity}

Five fruits were randomly selected and labeled for each plant and treatment. The equatorial diameter (D, mm) of fruits was measured from 04-54 d after full bloom (DAFB), using a digital caliper, with $\pm 0.03 \mathrm{~mm}$ precision (Electronic Digital Caliper, Altraco, Los Angeles, California, USA). To convert fruit diameter into fruit fresh weight, simultaneously to diameter measurement, a sample of 20 fruit was harvested and weighted from adjacent plants using a precision weighing scale (Precisa Instruments AG, Dietikon, Switzerland). The information was used to develop the following equation by regression 
analysis: $P=\left(a+b x^{2}\right)^{2}$, where $P$ is fruit fresh weight $(\mathrm{g}), a$ and $b$ are values of 0.180872 and 0.00473021 , respectively; $x$ corresponds to the equatorial diameter of the fruit, $\mathrm{r}^{2}$ $=0.95$. Absolute growth rate $\left(\mathrm{AGR}, \mathrm{g} \mathrm{d}^{-1}\right)$ and relative growth rate (RGR, $\mathrm{mg} \mathrm{g}^{-1} \mathrm{~d}^{-1}$ ) of fruits were estimated by the following relationships (Zibordi et al., 2009):

$$
A G R=\left(P t_{1}-P t_{0}\right) /\left(t_{1}-t_{0}\right) ; R G R=A G R / P t_{0}
$$

where $P t_{l}$ and $P t_{0}$ are weight values estimated at a given time $\left(t_{l}\right)$ and in the previous sampling $\left(t_{0}\right)$, respectively.

For fruit yield and precocity, fruit were picked gradually from 38 to 73 DAFB and at $7 \mathrm{~d}$ intervals. The harvest index was when the fruit turned on blue color. Fruit were weighed and counted and total cumulative yield was estimated.

\section{Statistical analysis}

The effect of the treatments was estimated by a simple ANOVA with a level of significance of 0.05 . Statistical analyses of data were performed using Statgraphics Centurion XVI software (StatPoint Technologies, Warrenton, Virginia, USA).

\section{RESULTS AND DISCUSSION}

\section{Environmental conditions}

Figure 1 shows the maximum and minimum temperatures recorded in the high tunnels and open fields. It can be observed that at 23 DAFB (close to the ripening period), the maximum temperature inside the tunnel exceeded by $12^{\circ} \mathrm{C}$ the one registered in open field (Figure 1A), which is consistent with the findings of Kadir et al. (2006) and Both et al. (2007). They reported that the maximum temperatures inside the high tunnels were up to $14^{\circ} \mathrm{C}$ higher. During the spring months (8 DAFB), minimum temperatures inside the high tunnels showed a tendency to increase between 1-5 ${ }^{\circ} \mathrm{C}$ compared to those recorded in the open fields, which coincide with those reported by Wien (2009) (Figure 1B).

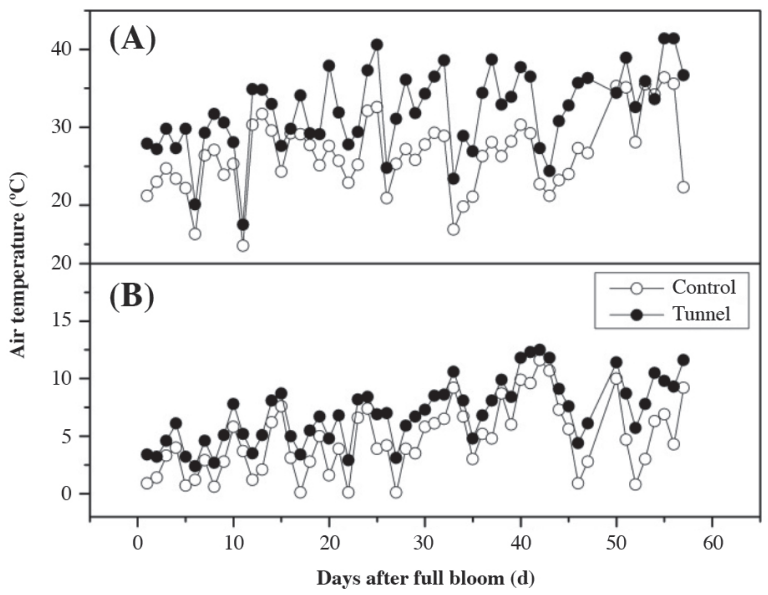

Figure 1. Variations in maximum (A) and minimum (B) air temperatures recorded in high tunnels and open fields (control) during the growing season 2011-2012 in Cabrero, Biobío Region, Chile.
The average minimum temperature (Figure 1B) inside the high tunnel during flowering and fruit set (10 a 55 DDPF) was $2{ }^{\circ} \mathrm{C}$ higher than the average of minimum temperature recorded in the open field (control). This is a relevant fact because studies have indicated that the most vulnerable period to lower temperatures for blueberries corresponds to the period elapsing from the start of flowering and petal fall (Michigan State University Extension, 2012), i.e. just after fruit set, which is time when fruit can be damaged at temperatures near $0{ }^{\circ} \mathrm{C}$. Wien (2009) and Santos and Salame-Donoso (2012) have indicated that the use of tunnels is an effective technique to protect plants against temperatures near or below $0{ }^{\circ} \mathrm{C}$. In the present study, the lowest temperatures in the open fields were near $0{ }^{\circ} \mathrm{C}$ in five different times (Figure 1B). Thus, the tunnel allowed protecting the fruit from five frost events during flowering and fruit development. Similarly, increased minimum temperatures in the high tunnels favor fertilization and fruit set since the threshold for pollinator activity, such as Apis mellifera fluctuates between 10 and $27{ }^{\circ} \mathrm{C}$ (Cooper and Schaffer, 1985), and is above $5^{\circ} \mathrm{C}$ for bumble bees (Bombus spp.) (Aras et al., 1996). A higher pollinator activity increases the size and the rate of fruit ripening significantly (Javorek et al., 2002). Furthermore, there were fewer events at temperatures below the flight threshold of pollinators inside the tunnels. This is a key factor since the period in which the flower exhibits the strongest stigmatic receptivity includes around $5 \mathrm{~d}$ (Brevis et al., 2006).

Figure 2 shows $\mathrm{RH}$ measurements recorded in the tunnel and open field trials. In general, maximum HR values (Figure 2A) were similar in both production systems, with average values of $99 \%$ for both of them. Nevertheless, a different pattern was observed for minimum HR values (Figure 2B). As observed in most of the period, the minimum HR in the tunnel was $10 \%$ and 20\% lower than in the open field (Figure 2B). These results differs with those obtained by Singh et al. (2012), who indicated that the HR is higher in crops under tunnels

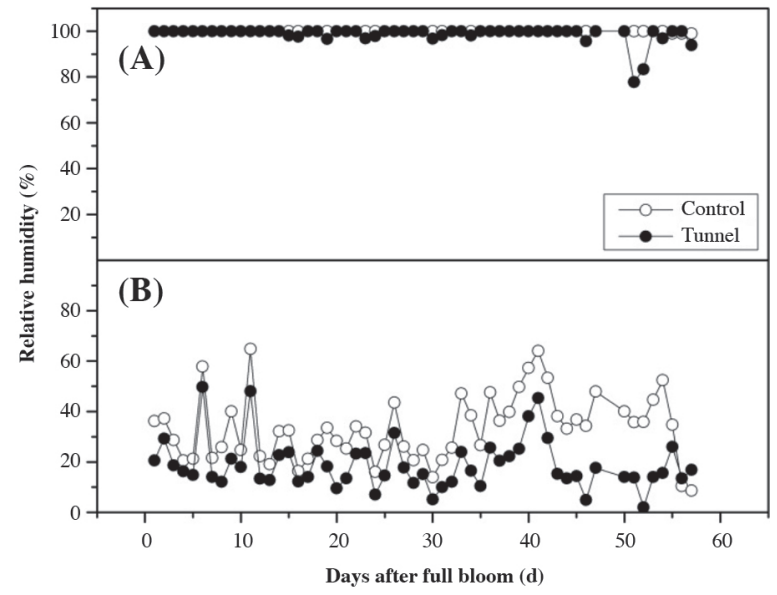

Figure 2. Variations in maximum (A) and minimum (B) relative humidity recorded in high tunnels and open fields (control) during the growing season 2011-2012 in Cabrero, Biobío Region, Chile. 
than in open fields. It is important to note that a high HR, despite the reduction of radiation (PAR), combined to higher temperature inside the tunnels could be increasing the atmospheric vapor pressure deficit and therefore the evapotranspiration crop demand (Allen et al., 2006).

\section{Radiation, stomatal conductance and chlorophyll fluorescence}

The high tunnel reduced $\mathrm{PAR}_{\text {total }}$ by an average $25 \%$ on sunny day conditions, when measured as photosynthetic photon flux density (PPFD) (Figure 3A). However, no significant differences were observed in the intensity of PAR between treatments on a partly cloudy day (Figure 3B) except at $16: 30 \mathrm{~h}$, the time in which a $25 \%$ reduction in $\mathrm{PAR}_{\text {total }}$ intensity was recorded in the tunnel. These values of reduced $\mathrm{PAR}_{\text {total }}$ are below those reported by Lobos et al. (2012) and Kim et al. (2011) in blueberries grown under shade net, and therefore the photosynthesis capacity should be not affected. Based on data of chlorophyll fluorescence (Figure 4), the calculated average of the maximum photochemical efficiency of PSII $\left(F_{\mathrm{v}} / F_{\mathrm{m}}\right)$ in dark-adapted leaves was 0.75 in the tunnel and 0.77 in the open field on a completely sunny day (Figure 4A), and 0.76 and 0.77 on a cloudy day, respectively (Figure 4B). No significant differences were found between the treatments, except at noon on a completely sunny day. The combination of high temperature and high radiation may affect photosynthetic efficiency (Barber and Anderson, 1992), as a photo-inhibition (Demmig-Adams, 1990). Some authors have described a correlation between photoinhibition and a decrease in the ratio of variable to maximum fluorescence of the Photosystem II (PSII), i.e., the $F_{\mathrm{v}} / F_{\mathrm{m}}$ ratio (Bolhàr-Nordenkampf and Öquist, 1993).

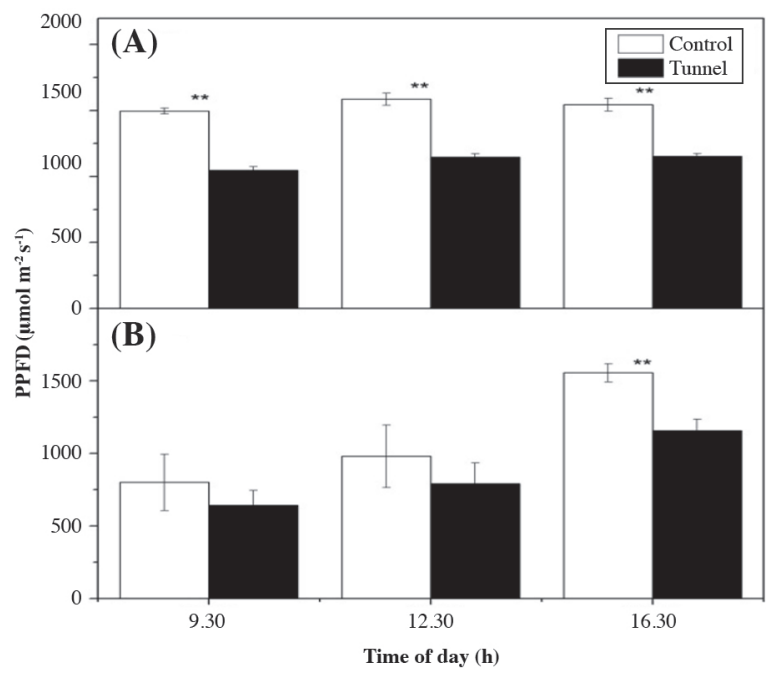

Each data point represents the mean $\pm \operatorname{SE}(n=10)$.

$* *$ Significant at $\mathrm{P}<0.01$.

Figure 3. Daytime changes of total photosynthetically active radiation $\left(\right.$ PAR $\left._{\text {total }}\right)$ in photosynthetic photon flux density (PPFD) in blueberries grown in high tunnels and open fields (control) on a completely sunny day (A) and a partially cloudy day (B).

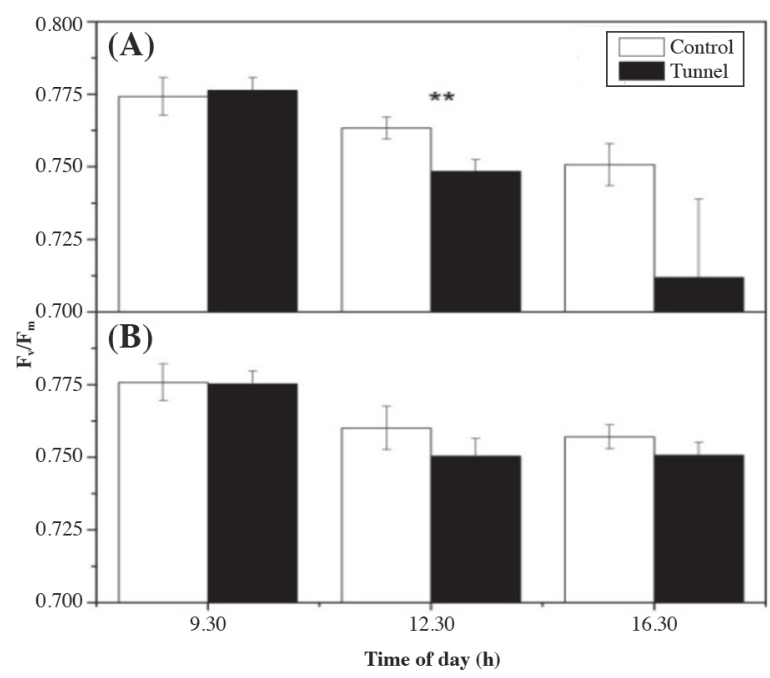

Each data point represents the mean \pm SE $(n=10)$.

$* *$ Significant at $\mathrm{P}<0.01$.

Figure 4. Quantum yield of photosystem II $\left(\mathrm{F}_{v} / \mathrm{F}_{\mathrm{m}}\right)$, dark-adapted in blueberries grown in high tunnels and open fields (control) on a completely sunny day (A) and a partially cloudy day (B).

Daily variations of the $F_{v} / F_{m}$ ratio indicate that plants grown in the open field (control) and those grown in the tunnel showed photoinhibition, since values were decreasing during the day (Figure 4A and 4B). However, $F_{\mathrm{v}} / F_{\mathrm{m}}$ values for plants in the tunnel were closer to 0.8 , which indicates that there was a greater photoinhibition level in the tunnel compared to the control. This was mainly observed on a completely sunny day, which can be attributed to high levels of PAR $_{\text {total }}$ associated with higher ambient temperature (Figures 1 and 3). Kitao et al. (2000) reported that increased leaf temperature increases susceptibility to photoinhibition. Similarly, the decrease in daytime $F_{v} / F_{m}$ ratio in the control plants probably depended on the $\mathrm{PAR}_{\text {total }}$ levels associated with high temperatures, reaching minimum values at around 16:30 h (Figure 3). However, the simultaneous decrease in $F_{\mathrm{v}} / F_{\mathrm{m}}$ ratio (Figure $4 \mathrm{~A}$ and $4 \mathrm{~B}$ ) and increase in temperature (Figure $1 \mathrm{~A}$ and $1 \mathrm{~B}$ ) and $\mathrm{PAR}_{\text {total }}$ (Figure $3 \mathrm{~A}$ and $3 \mathrm{~B}$ ) did not coincide with an increase in stomatal conductance in the high tunnels (Figure 5), on both sunny and cloudy days. On a sunny day, the average $g_{s}$ value was $99 \%$ higher in the tunnels compared to the open fields. Similarly, this value was $42 \%$ higher on a cloudy day (Figure 5B). Increased stomatal conductance is an indicator of higher gas exchange capacity of the leaf, including $\mathrm{CO}_{2}$ assimilation and plant transpiration (Rho et al., 2012). The high levels of stomatal conductance cannot be attributed to conditions of temperature (Figure 1) or RH (Figure 2) measured in the high tunnel, since it has been observed that an increase in temperature and decrease in $\mathrm{RH}$ usually promote a stomatal closure of leaves in several species of fruit trees (Jones and Lakso, 1995). PAR $_{\text {diffuse }}$ levels were significantly higher in the 


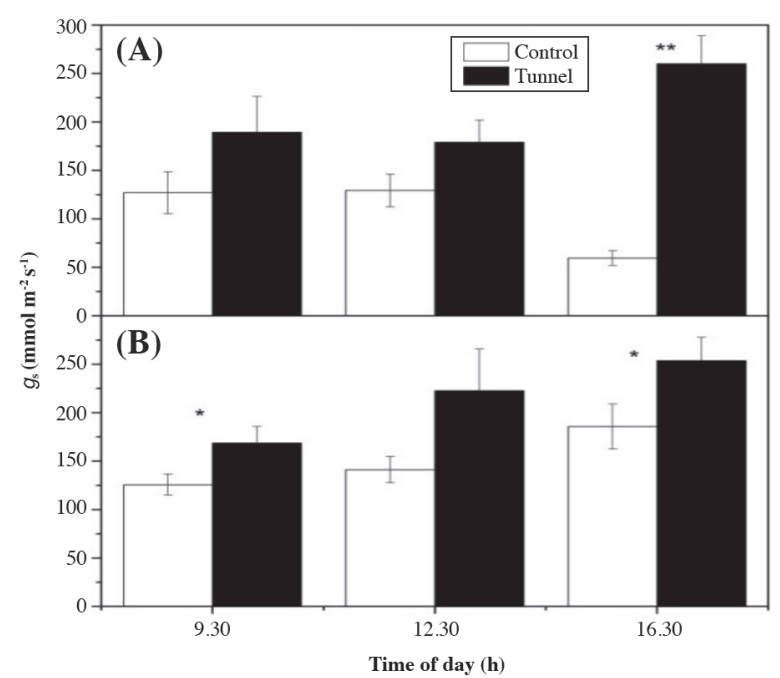

Each data point represents the mean \pm SE $(n=10)$.

$*$, **Significant at the 0.05 and 0.01 probability levels, respectively.

Figure 5. Daytime changes in stomatal conductance $\left(g_{s}\right)$ in blueberries grown in high tunnels and open fields (control) on a completely sunny day (A) and a partially cloudy day (B).

tunnels compared to the control (Figure 6). The amount of PAR diffuse $_{\text {was }}$ more than $200 \%$ higher on a sunny day (Figure 6A), and more than $150 \%$ higher on a cloudy day (Figure 6B) in the high tunnel when compared the open-field radiation. This increase in diffuse light in greenhouses or tunnels has been noted in other studies, indicating that the polyethylene used promotes a greater transformation of direct light into diffuse light, which results beneficial for photosynthesis and productivity in horticultural crops (Li et al., 2014).

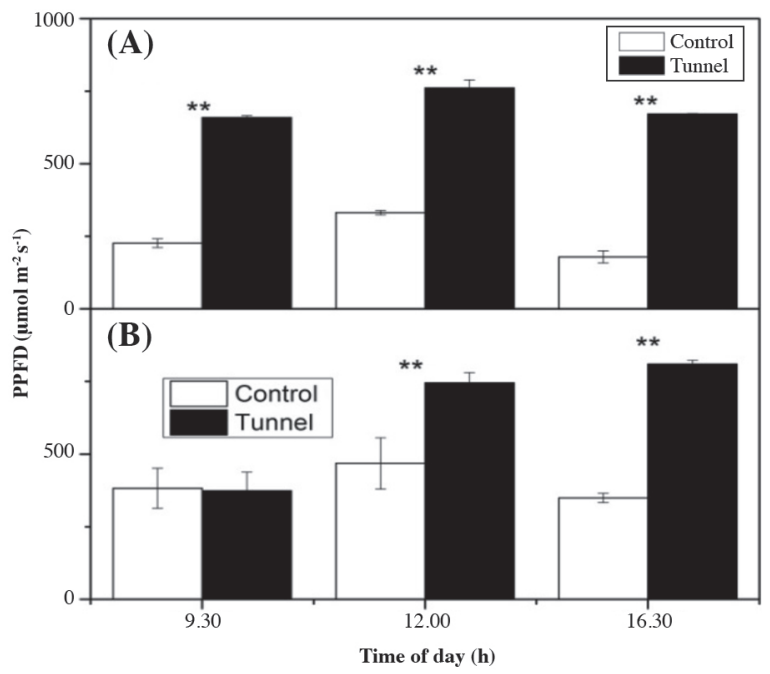

Each data point represents the mean $\pm \operatorname{SE}(n=10)$.

**Significant at $\mathrm{P}<0.01$.

Figure 6. Daytime changes of diffuse photosynthetically active radiation (PAR $\mathbf{R}_{\text {diffuse }}$ ) in photosynthetic photon flux density (PPFD) in blueberries grown in high tunnels and open fields (control) on a completely sunny day (A) and a partially cloudy day (B).
According to the regression analysis, a significant relationship $\left(\mathrm{r}^{2}=0.66^{* *}\right)$ was found between $\mathrm{PAR}_{\text {diffuse }}$ and leaf stomatal conductance, but not with the amount of PAR $_{\text {total }}$ (Figure 7). These results are consistent with recent studies that suggest that a greater distribution of diffuse radiation photons improve leaf gas exchange in several protected crops ( $\mathrm{Li}$ et al., 2014). The positive effect of diffuse radiation on the net gas exchange rate of trees can result in favorable microclimatic for the plant (reduced leaf temperature), promoting stomatal opening with an increase in the blue/red light rate, or with higher light penetration and distribution into the plant canopy (Urban et al., 2007). In this context, further research is required to determine how these specific conditions of diffused light in high tunnels affect photosynthesis and transpiration in blueberries.

\section{Fruit growth}

In this study, the whole fruit development period lasted approximately 53 to $66 \mathrm{~d}$ (Figure 8). These results agree with those reported by Retamales and Hancock (2012), who indicate that the whole period of fruit development in blueberries ranges from 55 to $60 \mathrm{~d}$, which is consistent with a double- sigmoid growth pattern typically exhibited by this species (Godoy et al., 2008). The use of tunnels showed no effect on the AGR or RGR of fruit during the first growth stage, which corresponded to the period between 6 and 11 DAFB. Then, AGR and RGR values in the tunnel were significantly higher in the period between 11 and 20 DAFB (Figure 8A and 8B), and significantly lower starting from 20 DAFB compared to the control.

It has been reported that high temperature and low $\mathrm{RH}$ conditions, as observed in this study (Figures 1 and 2), can reduce fruit expansion rate due to increased direct transpiration of the fruit resulting from high levels of vapor

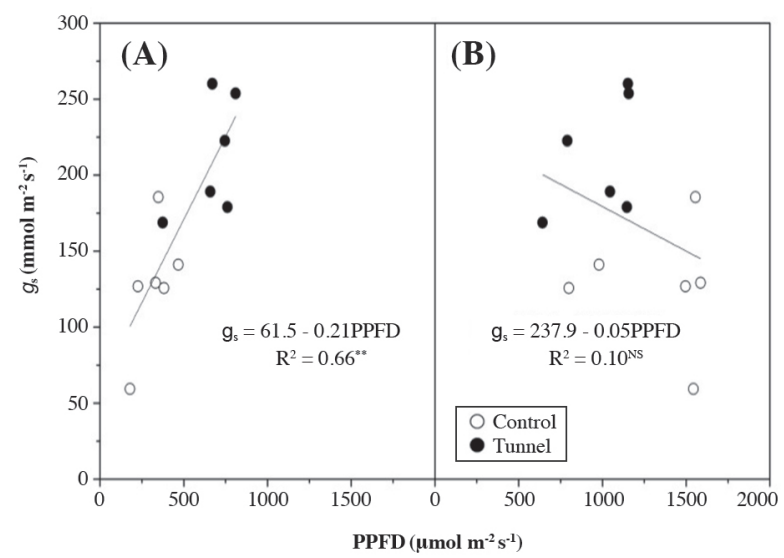

$* * \mathrm{P}<0.01$

Figure 7. Response of stomatal conductance $\left(g_{s}\right)$ to diffuse and total photosynthetically active radiation $\left(\mathbf{P A R}_{\text {diffuse }}\right)(\mathrm{A})$ and total photosynthetically active radiation $\left(\mathbf{P A R}_{\text {total }}\right)$ intensities $(\mathrm{B})$ in photosynthetic photon flux density (PPFD) for blueberries grown in high tunnels and open fields (control). 


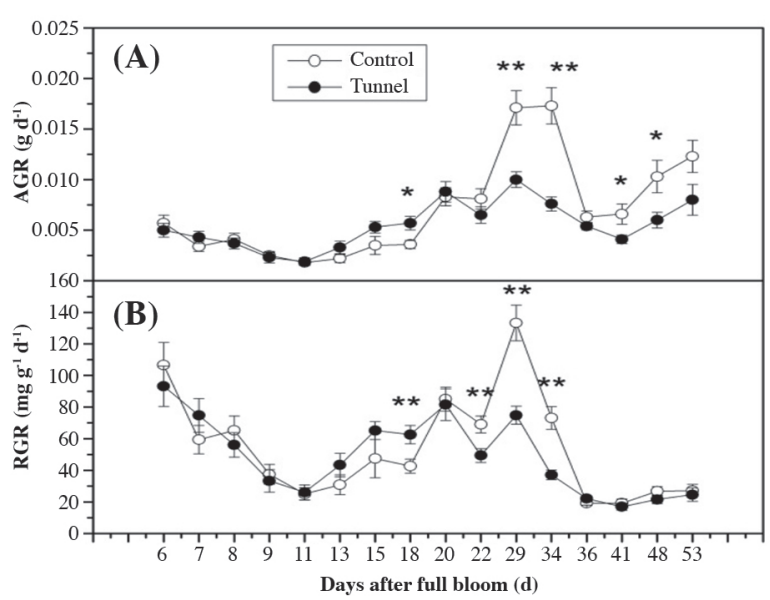

Each data point represents the mean \pm SE $(n=5)$.

*, **Significant at the 0.05 and 0.01 probability levels, respectively.

Figure 8. Absolute growth rate (AGR) (A) and relative growth rate (RGR) (B) of fruit in blueberries grown in high tunnels and open fields (control).

pressure deficit or excessive evaporative demand, and low leaf water potential (Lang, 1990). Recent studies on cherries show that AGR is closely related to the fruit cell expansion (Bastías et al., 2014), which indicates that high temperature and low RH in high tunnels could negatively affect the cell expansion rate of blueberries in their last growth stage (Figure 8). Moreover, the number of fruits per plant grown in high tunnels was significantly higher (Table 1). This has a direct effect on the carbohydrate distribution to the fruit, and thus on fruit growth rate. A greater number of fruits per plant can imply a reduction in AGR and RGR, as has been measured in other fruit species such as apple and peach (Zibordi et al., 2009).

Table 1. Yield components of blueberries grown in high tunnels and in open fields (control) $(n=24)$.

\begin{tabular}{lccc}
\hline & \multicolumn{3}{c}{ Yield components } \\
\cline { 2 - 4 } Treatments & Accumulated yield & Fruit weight & Crop load \\
\hline & 99.5 & $\mathrm{~g}$ & fruit plant $^{-1}$ \\
Tunnel & 69.0 & 1.2 & 81 \\
Control & $* *$ & 1.3 & 53 \\
Significance & & $\mathrm{ns}$ & $* *$ \\
\hline
\end{tabular}

** Significant at $\mathrm{P}<0.01$; ns: nonsignificant.

\section{Yield and precocity}

Harvesting of blueberries grown in high tunnels began at $38 \mathrm{DAFB}$, i.e. $14 \mathrm{~d}$ before fruit grown in the open field (Figure 9A). The cumulative yield per plant under tunnels was significantly higher and exceeded $44 \%$ that achieved in the open-field production (Figure 9A, Table $1)$. The use of high tunnels also affected the number of fruits that increased by $65 \%$ when compared to the control (Figure 9B, Table 1). These results agree with findings reported by Santos and Salame-Donoso (2012), who indicate that a yield increase of berries grown in high tunnels can be explained by a better fertilization and fruit set due to the increase in minimum temperature as demonstrated in this research (Figure 1). As can be

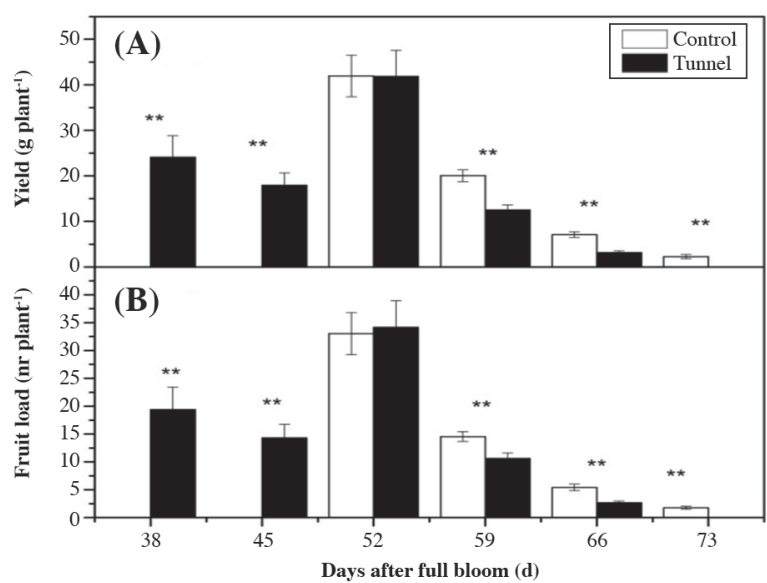

Each data point represents the mean \pm SE $(n=24)$. **Significant at $\mathrm{P}<0.01$.

Figure 9. Harvest distribution according to yield (A) and number of fruits (B) in blueberries grown in high tunnels and open fields (control).

observed in Figure 9, 42\% of all fruits produced under high tunnels had already been harvested when the harvest of fruits grown in the open field began. Ogden and van Iersel (2009) have also indicated that high tunnels modify climatic conditions, promoting earlier flowering and fruit ripening, as well as fruit precocity production. It is important to note that no significant differences were observed in fruit weight between fruit grown in high tunnels and in open-field (Figure 9B), with values of 1.2 and $1.3 \mathrm{~g}$, respectively (Table 1 ). This indicates that although significant differences were observed in the RGR and AGR of the fruit (Figure 8A and 8B), these had no effect on the final fruit weight at harvest (Table 1). In other fruit trees such as apple and peach it has been determined that the final fruit size is resulting of seasonal AGR and RGR variations during the whole season fruit development (Bastías et al., 2012). In the present study was observed that between 11-20 DAFB the AGR and RGR were significantly greater under high tunnel, which could be in part compensating the partial fruit weight losses measured after 20 DAFB (Figure 8).

\section{CONCLUSIONS}

The results of this study show that the increment of air temperature under high tunnels is an effective tool for improve yield and precocity in blueberry orchards, while the increment of the amount in photosynthetic diffuse light under tunnels can favor leaf stomatal conductance in blueberry plants.

\section{ACKNOWLEDGEMENTS}

The authors thank to Faculty of Agronomy, University of Concepcion, for the supporting and funding to develop the present research. 


\section{LITERATURE CITED}

Al-Helal, I.M., and A.M. Abdel-Ghany. 2010. Responses of plastic shading nets to global and diffuse PAR Transfer: Optical properties and evolution. Wageningen Journal of Life Science 57:125-132.

Allen, R.G., L.S. Pereira, D. Raes, y M. Smith. 2006. Evapotranspiración del cultivo: Guías para la determinación de requerimientos de agua de los cultivos. FAO, Roma, Italia.

Aras, P., D. Oliveira, and L. Savoie. 1996. Effect of a honey bee (Hymenoptera: Apidae) gradient on the pollination and yield of lowbush blueberry. Journal of Economic Entomology 89:1080-1083.

Barber, J., and B. Anderson. 1992. Too much of a good thing: light can be bad for photosynthesis. Trends in Biochemical Sciences 17:61-66.

Bastías, R.M., F. Diez, and V.L. Finot. 2014. Absolute and relative growth rates as indicators of fruit development phases in sweet cherry Prunus avium. Chilean Journal of Agricultural and Animal Science 30:89-98.

Bastías, R.M., L. Manfrini, and L. Corelli-Grappadelli. 2012. Exploring the potential use of photo-selective nets for fruit growth regulation in apple. Chilean Journal of Agricultural Research 72:224-231.

Bolhàr-Nordenkampf, H.R., and G. Öquist. 1993. Chlorophyll fluorescence as a tool in photosynthesis research. p. 193-206. In Hall, D.O., J.M.O. Scurlock, H.R. Bolhàr-Nordenkampf, R.C. Leegood, and S.P. Long (eds.) Photosynthesis and production in a changing environment. Springer, London, UK.

Both, A.J., J.F. Reiss, K.E. Sudal, C.A. Holmstrom, W.L. Kline, and S.A. Garrison. 2007. Evaluation of a manual energy curtain for tomato production in high tunnels. HortTechnology 17:467-472.

Brevis, P.A., D.S. NeSmith, H.Y. Wetzstein, and D.B. Hausman. 2006. Flower age affects fruit set and stigmatic receptivity in rabbiteye Blueberry. HortScience 41:1537-1540.

Carlen, C., and E. Krüger. 2009. Berry production in changing climate conditions and cultivation systems: further research requirements. Acta Horticulturae 838:225-228.

Cooper, P.D., and W.M. Schaffer. 1985. Temperature regulation of honey bees (Apis mellifera) foraging in the Sonoran Desert. Journal of Experimental Biology 114:1-15.

Corelli-Grappadelli,L., and A.N.Lakso. 2007. Is maximizing orchard light interception always the best choice? Acta Horticulturae 732:507-518.

Cowan, J.S., C.A. Miles, P.K. Andrews, and D.A. Inglis. 2014. Biodegradable mulch performed comparably to polyethylene in high tunnel tomato (Solanum lycopersicum L.) production. Journal of Science Food and Agriculture 94:1854-1864.

Demchak, K. 2009. Small fruit production in high tunnels. HortTechnology 19(1):44-49.

Demmig-Adams, B. 1990. Carotenoids and photoprotection in plants: A role for the xanthophyll zeaxanthin. Biochimica et Biophysica Acta 1020:1-24.

Godoy, C., G. Monterubbianesi, and J. Tognetti. 2008. Analysis of highbush blueberry (Vaccinium corymbosum L.) fruit growth with exponential mixed models. Scientia Horticulturae 115:368-376.

Javorek, S.K., K.E. Mackenzie, and S.P. Vander Kloet. 2002. Comparative pollination effectiveness among bees (Hymenoptera: Apoidea) on lowbush blueberry (Ericaceae: Vaccinium angustifolium). Annals of the Entomological Society of America 95:345-351

Jones, H.G., and A.N. Lakso. 1995. Physiological control of water status in temperate and subtropical fruit trees. Horticultural Reviews 7:301-344.

Kadir, S., E. Carey, and S. Ennahli. 2006. Influence of high tunnel and field conditions on strawberry growth and development. HortScience 41:329-335.

Kim, S.J., D.J. Yu, T. Kim, and H.J. Lee. 2011. Growth and photosynthetics of blueberry (Vaccinium corymbosum cv. Bluecrop) under various shade levels. Scientia Horticulturae 129:486-492.
Kitao, M., T.T. Lei, T. Koike, H. Tobita, and Y. Maruyama. 2000. Susceptibility to photoinhibition of three deciduous broadleaf tree species with different successional traits raised under various light regimes. Plant, Cell \& Environment 23:81-89.

Lang, A. 1990. Xylen, phloem and transpiration flows in developing apple fruits. Journal of Experimental Botany 41(227):645-651.

Li, X., W. Chen, and Y. Li. 2012. Study on photosynthetic characteristics of blueberry in greenhouse. Acta Horticulturae 926:315-320.

Li, T., E. Heuvelink, T.A. Dueck, J. Janse, G. Gort, and L.F.M. Marcelis. 2014. Enhancement of crop photosynthesis by diffuse light: quantifying the contributing factors. Annals of Botany 114:1-12.

Lobos, G.A., J.B. Retamales, J.F. Hancock, J.A. Flore, N. Cobo, and A. del Pozo. 2012. Spectral irradiance, gas exchange characteristics and leaf traits of Vaccinium corymbosum L. 'Elliott' grown under photo-selective nets. Environmental and Experimental Botany 75:142-149.

Medina, C.L., R.P. Souza, E.C. Machado, R.V. Rivero, and J.A.B. Silva. 2002. Photosynthetic response of citrus grown under reflective aluminized polypropylene shading nets. Scientia Horticulturae 96:115-125.

Michigan State University Extension. 2012. Growth stages table. Available at http://blueberries.msu.edu/growing_blueberries/ growth_stages_table (accessed 21 June 2013). Michigan Blueberry Facts, Michigan State University, East Lansing, Michigan, USA.

Ogden, A.B., and M.W. van Iersel. 2009. Southern highbush blueberry production in high tunnels: temperatures, development, yield, and fruit quality during the establishment years. HortScience 44:1850-1856.

Retamales, J.B., and J.F. Hancock. 2012. Blueberries. CABI, Cambridge, USA.

Reyes-Diaz, M., M. Alberdi, and M.L. Mora. 2009. Short-term aluminum stress differentially affects the photochemical efficiency of photosystem II in highbush blueberry genotypes. Journal of the American Society for Horticultural Science 134:14-21.

Rho, H., J.D. Yu, S.J. Kim, and J.H. Lee. 2012. Limitation factors for photosynthesis in 'Bluecrop' highbush blueberry (Vaccinium corymbosum) leaves in response to moderate water stress. Journal of Plant Biology 55:450-457.

Righi, E.Z., G.A. Buriol, L.R. Angelocci, A.B. Heldwein, and I.F. Tazzo. 2012. Relationships of photosynthetic photon flux density, air temperature and humidity with tomato leaf diffusive conductance and temperature. Brazilian Archives of Biology and Technology 55:359-370.

Sandri, M.A., J.L. Andriolo, M. Witter, and T. Dal Ross. 2003. Effect of shading on tomato plant grow under greenhouse. Horticultura Brasileira 21:642-645.

Santos, B.M., and P.T. Salame-Donoso. 2012. Performance of southern highbush blueberry cultivars under high tunnels in Florida. HortTechnology 22:700-702.

Singh, A., A. Syndor, B.C. Deka, R.K. Singh, and R.K. Patel. 2012. The effect of microclimate inside low tunnels on off-season production of strawberry (Fragaria xananassa Duch.) Scientia Horticulturae 144:36-41.

Sudzuki,F. 2002. Cultivo de frutales menores. Editorial Universitaria, Santiago, Chile.

Urban, O., D. Janous, M. Acosta, R. Czerny, I. Markova, M. Navratil, et al. 2007. Ecophysiological controls over the net ecosystem exchange of mountain spruce stand. Comparison of the response in direct vs. diffuse solar radiation. Global Change Biology 13:157-168.

van Kooten, O., and J.H. Snel. 1990. The use of chlorophyll fluorescence nomenclature in plant stress physiology. Photosynthesis Research 25:147-150.

Wien, H.C. 2009. Microenvironmental variations within the high tunnel. HortScience 44:235-238.

Zhao, Y., M. Gu, G. Bi, B. Evans, and R. Harkess. 2014. Planting date effect on yield of tomato, eggplant, pepper, zinnia, and snapdragon in high tunnel in Mississippi. Journal of Crop Improvement 28:27-37.

Zibordi, M., S. Domingos, and L. Corelli-Grappadelli. 2009. Thinning apples by shading: an appraisal under field conditions. Journal of Horticultural Science and Biotechnology (ISAFRUIT special issue): $138-144$ 